\title{
Briefly Noted
}

Fully Human: Personhood, Citizenship, and Rights, Lindsey N. Kingston (New York:

Oxford University Press, 2019), 312 pp., \$65 cloth, \$64.99 eBook.

doi:10.1017/So892679419000546

It is still true in the twenty-first century that national citizenship represents an individual's so-called "right to have rights," and that beyond this legal status, citizenship fosters the immaterial bond between the state and the individual that provides respect and protection of human dignity. But, as Lindsey N. Kingston posits in Fully Human, individuals existing outside this type of political community are often deprived of their personhood and fundamental rights -deprived of their full humanness. When rights to place and purpose (in other words, the right to citizenship and contingent rights, such as education) are denied from birth, when the connection between state and individual disintegrates, or when the contractual promise of citizenship simply ceases to function, there must be an alternative.

For Kingston, the alternative is found in a new theory of "functioning citizenship" that aims to open a political space for citizens, noncitizens, and every classification in between. This theory of functioning citizenship recognizes that it is no longer feasible or ethical to consider citizenship as a binary of citizenship and noncitizenship, because the gray space in between facilitates routine rights violations. For instance, Kingston draws a critical connection between the vulnerability derived from lacking functional citizenship and the increased risk of crimes of peace, such as human trafficking. The solution, she argues, is to embrace a more accurate conceptualization of noncitizenship: individuals may be considered de jure noncitizens, but they still have agency and, critically, are still worthy of full personhood and membership in a political community.

The book proceeds through an exploration of several distinct devalued groups who most frequently fall victim to "hierarchies of personhood," or the inequalities that render some people less worthy of protections and political membership than others. Stateless people, the forcibly displaced, irregular migrants, indigenous peoples, and even "second-class" citizens in the United States-groups typically considered separately in international politics and law - are considered alongside one another, to illustrate that they all share an important common denominator: they cannot call upon a state apparatus, whether it is their state of national origin, host state, or otherwise, for full protection. Integrating the bodies of literature on these various social groups, Kingston's exhaustive research demonstrates the saliency of centering these divergent fields under a single theme.

Ethics \& International Affairs, 33, no. 4 (2019), pp. 521-522.

(c) 2019 Carnegie Council for Ethics in International Affairs 
Although the book remains mostly in the theoretical realm as it advocates for functioning citizenship, Kingston concludes by offering several practical recommendations as well. Much of what she presents are conventional ideals, including ensuring fairness in legal processes, fostering human rights education and encouraging state accession to human rights law and norms, empowering marginalized communities, and utilizing "best practices" in refugee or migrant integration. However, she also offers some new, concrete policy suggestions such as providing universal identification documents, rejecting denationalization as a weapon or form of punishment, and emphasizing rights entitlements over charity models.
In an era marked by "us vs. them" rhetoric and a perpetual impasse in the theoretical debate over cosmopolitan duties to strangers, Fully Human will appeal to those who recognize that assuaging the human consequences of conflict and globalization requires conceptual clarity that combines the idealistic with the pragmatic. This book walks that line, advocating an expanded form of political membership that transcends borders and passports, while also appreciating the authority of the state. Kingston shows us that traditional notions of citizenship cannot afford universal, fundamental rights protection, and makes a compelling argument that it is time to re-envision a system that can. 